\title{
HDAC inhibitors with potential to overcome drug resistance in castration-resistant prostate cancer
}

\author{
Bernhard Biersack¹, Bianca Nitzsche ${ }^{2}$, Michael Höpfner ${ }^{2}$ \\ 'Organic Chemistry Laboratory, University of Bayreuth, Bayreuth 95440, Germany. \\ ${ }^{2}$ Institute of Physiology, Charité-Universitätsmedizin Berlin, Berlin 10117, Germany.
}

Correspondence to: Dr. Bernhard Biersack, Organic Chemistry Laboratory, University of Bayreuth, Universitätsstrasse 30, Bayreuth 95440, Germany. E-mail: bernhard.biersack@yahoo.com; bernhard.biersack@uni-bayreuth.de

How to cite this article: Biersack B, Nitzsche B, Höpfner M. HDAC inhibitors with potential to overcome drug resistance in castration-resistant prostate cancer. Cancer Drug Resist 2022;5:64-79. https://dx.doi.org/10.20517/cdr.2021.105

Received: 28 Sep 2021 First Decision: 22 Nov 2021 Revised: 7 Dec 2021 Accepted: 15 Dec 2021 Published: 4 Jan 2022

Academic Editors: Godefridus J. (Frits) Peters, Sanjay Gupta Copy Editor: Xi-Jun Chen Production Editor: Xi-Jun Chen

\begin{abstract}
Epigenetic mechanisms play an important role in the development and persistence of cancer, and histone deacetylase (HDAC) inhibitors are promising anticancer drugs targeting epigenetic modes. Efficient anticancer drugs for the treatment of castration-resistant prostate cancer (CRPC) are sought, and approved HDAC inhibitors have shown promising results on the one hand and severe drawbacks on the other hand. Hence, ways to break the drug resistance mechanisms of existing HDAC inhibitors as well as the design of new promising HDAC inhibitors which can overcome the disadvantages of the classic HDAC inhibitors are of great importance. In this work, HDAC inhibitors with the potential to become a mainstay for the treatment of CRPC in the future as well as suitable combination treatments of HDAC inhibitors with other anticancer drugs leading to considerable synergistic effects in treated CRPCs are discussed.
\end{abstract}

Keywords: Histone deacetylases, HDAC inhibitors, castration-resistant prostate cancer, drug resistance

\section{INTRODUCTION}

More than 1.2 million new cases of prostate cancer cases are reported per year worldwide (2018) rendering prostate cancer the second most diagnosed cancer in men along with a rising incidence over the last years ${ }^{[1]}$. The formation of metastases dramatically reduces the survival rates in prostate cancer patients ${ }^{[2]}$. Advanced 
forms of prostate cancer are commonly treated by hormone therapy, either by surgical castration or by chemotherapy targeting hormone release ${ }^{[3]}$. However, patients develop castration-resistant prostate cancer (CRPC) forms within a median time of two years after treatment, which pose a life-threatening danger to affected patients with distinctly poorer prognosis ${ }^{[4]}$. CRPC can occur in metastatic (mCRPC) and nonmetastatic (MoCRPC) forms. Clinical trials using anti-androgen therapies with drugs such as apalutamide, enzalutamide, or darolutamide showed promising outcomes and significantly prolonged metastasis-free survival in MoCRPC patients ${ }^{[5-7]}$. Treatment options for mCRPC patients include taxanes such as docetaxel and cabazitaxel as well as various anti-androgens (bicalutamide and enzalutamide) ${ }^{[8]}$. The development of the selective CYP17 inhibitor abiraterone and its prodrug abiraterone acetate, specifically blocking androgen synthesis and androgen receptors via CYP17 enzyme inhibition, has led to another valuable first-line treatment option for mCRPC patients ${ }^{[9]}$.

Chromatin remodeling is a crucial mechanism in proliferating cells and affects transcription, replication, and DNA repair processes. The nucleosome is the basic unit of chromatin and consists of the positively charged histone core octamer proteins $\left(\mathrm{H}_{2} \mathrm{~A}, \mathrm{H} 2 \mathrm{~B}, \mathrm{H} 3\right.$, and $\mathrm{H} 4$, each twice per octamer) wrapped by DNA of 147 base pairs and one attached $\mathrm{H} 1$ histone ${ }^{[10,1]}$. $\mathrm{N}$-terminal lysines of the histones are crucial for their DNA interaction, and the charge of these lysines is regulated by cellular $\mathrm{N}$-acetylation processes. Acetylation of histones reduces their interaction with DNA leading to chromatin decondensation and gene transcription, while histone deacetylation silences gene expression in the densely packed chromatin ${ }^{[12]}$. Histone modifying enzymes such as histone acetyl transferases (HATs), which catalyze lysine acetylation, and histone deacetylases (HDACs), which catalyze the removal of acetyl groups from target protein lysines, play an eminent role in these processes and, in particular, inhibitors of HDACs were developed as anticancer agents ${ }^{[13]}$. The scope of HDAC inhibitors is promising since they also affect the acetylation state of non-histone proteins, such as p53, Hsp90, STAT3, and NF- $\mathrm{BB}$, and regulate the stability and/or DNA binding properties of these non-histones in this way with significant effects on, for instance, gene transcription, cell division, signal transduction, DNA repair, and apoptosis induction ${ }^{[14,15]}$. In terms of HDACs and prostate cancers, the HDAC-based regulation of the androgen receptor (AR) via the acetylation state of Hsp9o is especially interesting and of high relevance for the design of HDAC inhibitor-based prostate cancer therapies for patients with poor prognosis (see below) ${ }^{[15,16]}$. N-Methylation of lysines is another regulatory modification of histones controlled by lysine demethylases (KDMs), which can have silencing and activating effects on gene transcription in cancers ${ }^{[17]}$. KDMA1 (LSD1) has oncogenic functions in prostate cancers by AR co-activation, suppression of p53, and activation of c-Myc expression, and the development of KDM inhibitors as anticancer agents (e.g., cyclopropylamines) paves the way to promising epigenetic treatment options. The combination of KDM1 A and HDAC inhibitors showed synergistic effects on glioblastoma cells ${ }^{[17]}$. The HDAC inhibitor vorinostat also inhibited $\mathrm{EZ}_{2} \mathrm{H}$ and $\mathrm{H}_{3} \mathrm{~K} 4$ demethylases in the micromolar concentration range ${ }^{[17-19]}$.

A few HDAC inhibitors have already reached clinical application and are used for the treatment of multiple myeloma (panobinostat) and T-cell lymphoma (vorinostat, romidepsin, and belinostat); however, the performance of these first-generation HDAC inhibitors in solid tumors is rather poor ${ }^{[20]}$. Nevertheless, HDACs can be suitable anti-prostate cancer drug targets. HDAC1, for instance, was found to be upregulated in hormone refractory prostate cancer ${ }^{[21]}$. HDAC1, -2 , and -3 expression was associated with Ki-67-positive prostate cancer cell fractions, and high HDAC2 levels were detected in patients with reduced disease-free survival ${ }^{[22]}$. HDACs are necessary for functional AR signaling in prostate cancers, and HDAC inhibitors such as vorinostat and panobinostat blocked AR function by reducing AR expression and inhibiting coactivator/RNA polymerase II complex formation after AR binding to its DNA target element $^{[23]}$. Resistance mechanisms of prostate cancers to HDAC inhibitor treatment comprise the 
upregulation of detoxifying P-glycoprotein (P-gp) transporters, increased expression of HDAC enzymes, suppression of HAT enzymes, and upregulation of tumorigenic p21 (p21 is usually a tumor suppressor, but oncogenic functions of 21 were reported upon HDAC treatment $)^{[24]}$. HDAC inhibitors also induced epithelial-to-mesenchymal transition (EMT) in prostate cancers, which might be another reason for the drawbacks of HDAC inhibitors in solid tumors ${ }^{[25]}$.

HDAC enzymes can be subdivided into four classes. Classes I (HDAC1, -2, -3, -8), IIa (HDAC4, -5, -7, and -9), IIb (HDAC6 and -10), and IV (HDAC11) are metal-dependent with a catalytic zinc ion in the active site, while Class III HDACs (sirtuins) are not dependent on metals ${ }^{[2,22]}$. Due to the catalytic zinc ion of Class I, II, and IV HDACs, many HDAC inhibitors have a molecular zinc-binding group (ZBG) such as carboxylates, hydroxamic acids, benzamides, substituted ketones, mercaptoacetamides, or depsipeptides ${ }^{[28]}$. The modular composition of most HDAC inhibitors comprising a ZBG and a capping group connected by a linker allows the fine-tuning of HDAC inhibitors in terms of pharmacokinetics and anticancer activity ${ }^{[28]}$. Several dual or multimodal HDAC inhibitors have been reported, which showed improved anticancer activities especially against solid tumors ${ }^{[2,30]}$. This development is still ongoing and offers interesting compounds for the treatment of drug-resistant CRPC where first-generation HDAC inhibitors failed to perform.

This review provides the current state of the art of HDAC inhibitors under investigation in CRPCs and the potential of HDAC inhibitors to overcome drug resistance in this severe cancer form. A focus is set on next generation HDAC inhibitors with improved biological properties.

\section{HDAC INHIBITORS IN CRPC CLINICAL TRIALS}

Several clinical trials with HDAC inhibitors were carried out to monitor advantages and problems of the usage of HDAC inhibitors in the clinics. The clinical trials of HDAC inhibitors for the treatment of castration-resistant prostate cancer diseases were recently reviewed, and only the main outcomes are summarized in Table 1 and Figure $1^{[2,31]}$.

The depsipeptide romidepsin underwent a phase 2 clinical trial with 35 CRPC patients. Intravenous romidepsin treatment $\left(13 \mathrm{mg} / \mathrm{m}^{2}\right)$ led to radiological partial response in two patients and stable disease in 11 patients, while 22 patients showed progressive disease. Although no grade 4 toxicities were observed, 11 patients had to abandon the trial early, and, thus, romidepsin was not recommended for further phase 3 trials for $\mathrm{CRPC}^{[32]}$.

The hydroxamic acid vorinostat (400 mg/day, p.o.) showed drug-induced toxicities in 11 out of 27 CRPC patients during a phase 2 trial, who had to be removed from the study, while its anticancer activity was poor: only 2 patients had stable disease and 13 patients showed disease progression ${ }^{[33]}$. It seems that high IL-6 levels contributed to the failure of vorinostat in the patients with progressive CRPC disease.

Similar to romidepsin, the hydroxamate derivative panobinostat underwent a phase 2 trial with 35 CRPC patients. Intravenous panobinostat administration $\left(20 \mathrm{mg} / \mathrm{m}^{2}\right)$ led to PSA (prostate-specific antigen) reduction in only $14 \%$ of the patients and disease progression in 29 out of 35 patients $^{[34]}$. A phase 1 study of orally administered panobinostat compared with oral panobinostat in combination with docetaxel and prednisone showed only PSA reduction effects in five out of eight CRPC patients of the combination arm of the trial ${ }^{[35]}$. The oral panobinostat monotherapy showed no effects, and, thus, future studies should include combination therapies with suitable anticancer drugs. A combination study with oral panobinostat and bicalutamide (phase $1 / 2$ trial) in nine CRPC patients led to stable PSA levels in three patients and to PSA 
Table 1. CRPC clinical trials of HDAC inhibitors

\begin{tabular}{|c|c|c|c|c|}
\hline Drug(s) & Trial & $n$ & Dosage & Outcome \\
\hline Romidepsin $^{[32]}$ & Phase 2 & 35 & $30 \mathrm{mg} / \mathrm{m}^{2}$ (i.v.) & $\mathrm{PR}=2 ; \mathrm{SD}=11 ; \mathrm{PD}=22$ \\
\hline Vorinostat $^{[33]}$ & Phase 2 & 27 & $400 \mathrm{mg} /$ day (p.o.) & $\mathrm{SD}=2 ; \mathrm{PD}=13$ \\
\hline Panobinostat ${ }^{[34]}$ & Phase 2 & 35 & $20 \mathrm{mg} / \mathrm{m}^{2}$ (i.v.) & $\mathrm{SD}=4 ; \mathrm{PSA}$ reduction $=5 ; \mathrm{PD}=29$ \\
\hline $\begin{array}{l}\text { Panobinostat } \\
(+ \text { Docetaxel and Prednisone })^{[35]}\end{array}$ & Phase 1 & 8 & 15 or $20 \mathrm{mg} 3 \times$ per week (p.o.) & PSA reduction $=5$ \\
\hline $\begin{array}{l}\text { Panobinostat } \\
(+ \text { Bicalutamide })^{[36]}\end{array}$ & Phase 1 & 9 & 60,90 , or $120 \mathrm{mg} /$ week (p.o.) & Stable PSA $=3 ;$ PSA reduction $=4$ \\
\hline $\begin{array}{l}\text { Panobinostat } \\
(+ \text { Bicalutamide })^{[37]}\end{array}$ & Phase 2 & 29 & 40 mg triweekly for 2 weeks (p.o.) & $r P F=47.5 \%$; median time to $r P=33.9$ weeks \\
\hline Pracinostat ${ }^{[38]}$ & Phase 2 & 32 & 60 mg, 3× per week (p.o.) & $\mathrm{SD}=7 ; \mathrm{PSA}$ reduction $=2$ \\
\hline
\end{tabular}

PR: Partial response; SD: stable disease; PD: progressing disease; PSA: prostate-specific antigen; rP: radiographic progression; rPF: radiographic progression-free.

reduction of more than $50 \%$ in two patients ${ }^{[36]}$. The phase 2 trial of oral panobinostat (40 $\mathrm{mg}$ triweekly for two weeks) with oral bicalutamide showed promising results in CRPC patients, who were resistant to second-line antiandrogen therapy (2ndLAARx $)^{[37]}$. This combination treatment was well tolerated and led to a distinct number of radiographic progression-free patients $(47.5 \%)$ and prolonged median time to radiographic progression $(\mathrm{rP})$ in treated CRPC patients (33.9 weeks). In addition, five patients showed PSA decline of more than $30 \%$. The results indicate that panobinostat plus bicalutamide overcomes androgen resistance in a considerable number of CRPC patients. It is remarkable that panobinostat was less toxic to patients than other HDAC inhibitors such as romidepsin and vorinostat.

Pracinostat, which has received orphan drug status by the FDA for the treatment of AML, was also studied in a clinical phase 2 trial with 32 CRPC patients. Although only two patients displayed PSA reductions of more than $50 \%$, the drug $(60 \mathrm{mg}, 3 \times$ per week, p.o.) was well tolerated, led to stable disease in $22 \%$ of the patients, and reduced the number of circulating tumor cells in nine patients ${ }^{[38]}$.

In brief, the cinnamoyl derivatives panobinostat and pracinostat showed improved toxicity profiles and led to certain antitumor responses in CRPC patients, in particular, when combined with other drugs such as docetaxel or bicalutamide (in the case of panobinostat). In contrast, vorinostat and romidepsin showed drug-induced toxicities in a considerable number of patients who had to stop treatment with these drugs because of them. The relatively meager responses caused by the mentioned first-generation HDAC inhibitors in CRPC patients when applied as a monotherapy is the reason why no phase 3 studies in CRPC patients have been completed for these drugs until today.

\section{STRATEGIES TO IMPROVE HDAC INHIBITOR ACTIVITIES IN CRPC}

To overcome the clinical drawbacks of the first-generation HDAC inhibitors, a thorough elucidation of HDAC inhibitor mechanisms apart from or in consequence of HDAC inhibition is necessary, in particular, in combination with other anticancer drugs. In addition, the development of new tuned HDAC inhibitors appears to be promising in terms of improved clinical outcome. The most relevant research outcomes are provided below.

\section{HDAC inhibitor mechanisms beyond HDAC}

HDAC inhibition can lead to certain downstream effects in prostate cancer cells [Figure 2, Table 2]. The chemical structures of the investigated compounds are shown in Figure 1. The endogenous HDAC1 inhibitor protein maspin (mammary serine protease inhibitor), which was induced by the HDAC inhibitor 
Clinically studied HDAC inhibitors for CRPC treatment:
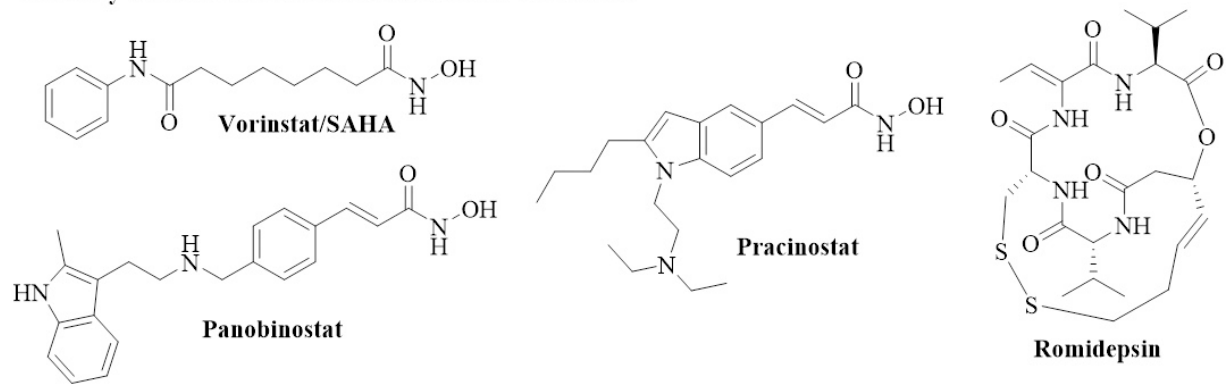

Further preclinically studied HDAC inhibitors:

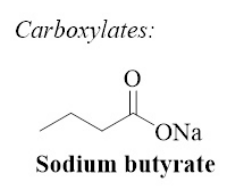

Sodium butyrate

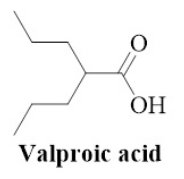

Valproic acid<smiles>Nc1ccccc1NC(=O)c1ccc(CNC(=O)OCc2cccnc2)cc1</smiles>

Entinostat

Further preclinically studied HDAC inhibitors:

Carboxylates:

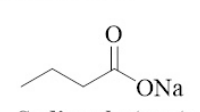

Sodium butyrate

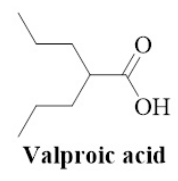<smiles>CC(C)CC(=O)c1ccc(CNC(=O)OCc2cccnc2)cc1</smiles>

Entinostat

Hydroxamic acids:<smiles>CC(=C/C(C)C(=O)c1ccc(N(C)C)cc1)/C=C/C(=O)NO</smiles><smiles>O=C(/C=C/c1ccc(CN(CCO)CCc2c[nH]c3ccccc23)cc1)NO</smiles><smiles>O=C(/C=C/c1cccc(S(=O)(=O)Nc2ccccc2)c1)NO</smiles><smiles>O=C(O)CCCCCCNC(=O)c1cnc(N(c2ccccc2)c2ccccc2)nc1</smiles>

Figure 1. Structures of clinically and preclinically tested HDAC inhibitors. HDAC: Histone deacetylase; CRPC: castration-resistant prostate cancer.

entinostat, suppressed AR expression in prostate cancers and led to sensitization of androgen-sensitive LNCaP and castration-resistant $22 \mathrm{Rv} 1$ prostate cancer cells to enzalutamide treatment ${ }^{[39]}$.

Acetylation of Hsp9o is regulated by cytoplasmic HDACs such as HDAC6, while Hsp9o regulates AR activity and stability in prostate cancers ${ }^{[40]}$. Hormone treatment induced castration-resistant phenotype and upregulated HDAC6 expression in prostate cancer cells. Belinostat (PXD101) suppressed Hsp90 activity, GSK-3 $\beta$, and AR function by HDAC6 inhibition and prevented the development of castration-resistant phenotype in prostate cancer cells. In addition, belinostat ( $40 \mathrm{mg} / \mathrm{kg}$ bid, i.p.) showed improved activities in $22 \mathrm{Rv} 1 \mathrm{CRPC}$ xenograft models in combination with the androgen antagonist bicalutamide $(50 \mathrm{mg} / \mathrm{kg} \text {, p.o. })^{[41]}$. Dacinostat (LAQ824), a close analog of panobinostat, suppressed the Hsp90 client 
Table 2. HDAC inhibitor effects beyond HDAC inhibition in prostate cancers

\begin{tabular}{|c|c|c|}
\hline HDAC inhibitor & Effect(s) & Cell lines/tumor models \\
\hline Belinostat $^{[41]}$ & Hsp90, AR, and GSK-3ß suppression & LNCaP, C4-2B, 22Rv1 \\
\hline Dacinostat ${ }^{[42]}$ & AR degradation by high acetyl-Hsp90, Akt inactivation & LNCaP \\
\hline Entinostat $^{[39]}$ & AR suppression, enzalutamide sensitization & LNCaP, 22Rv1 \\
\hline Entinostat $^{[43]}$ & $\begin{array}{l}\text { IFN } \gamma \text { production, suppressed Foxp3, upregulated acetyl-STAT3, } \\
\text { increased survivin vaccine activity }\end{array}$ & CR Myc-CaP \\
\hline Panobinostat ${ }^{[46]}$ & $\begin{array}{l}\text { HMGA2 suppression, EMT formation, increase of acetyl-p53 and } \\
\text { acetyl-AR }\end{array}$ & PKV, MES-like cells/tumors \\
\hline Trichostatin $A^{[44]}$ & Upregulated FGF8 and NF- $\mathrm{KB}$ & PC3M \\
\hline $\begin{array}{l}\text { Trichostatin A and sodium } \\
\text { butyrate }\end{array}$ & Upregulated CD133 & $\begin{array}{l}\text { Prostate cancer derived primary } \\
\text { endothelial cultures }\end{array}$ \\
\hline
\end{tabular}

Hsp90: Heat shock protein 90; AR: androgen receptor; IFN $\gamma$ : interferon- $\gamma$; STAT3: signal transducer and activator of transcription 3; CR: castration-resistant; HMGA2: high mobility group AT-hook 2; EMT: epithelial-to-mesenchymal transition; MES: mesenchymal; PC3M: metastatic PC3 cells; PKV: Pten ${ }^{\mathrm{L} / \mathrm{L}}, \mathrm{Kras}^{\mathrm{G}}{ }^{2 \mathrm{D} /+}$, Vim-GFP.
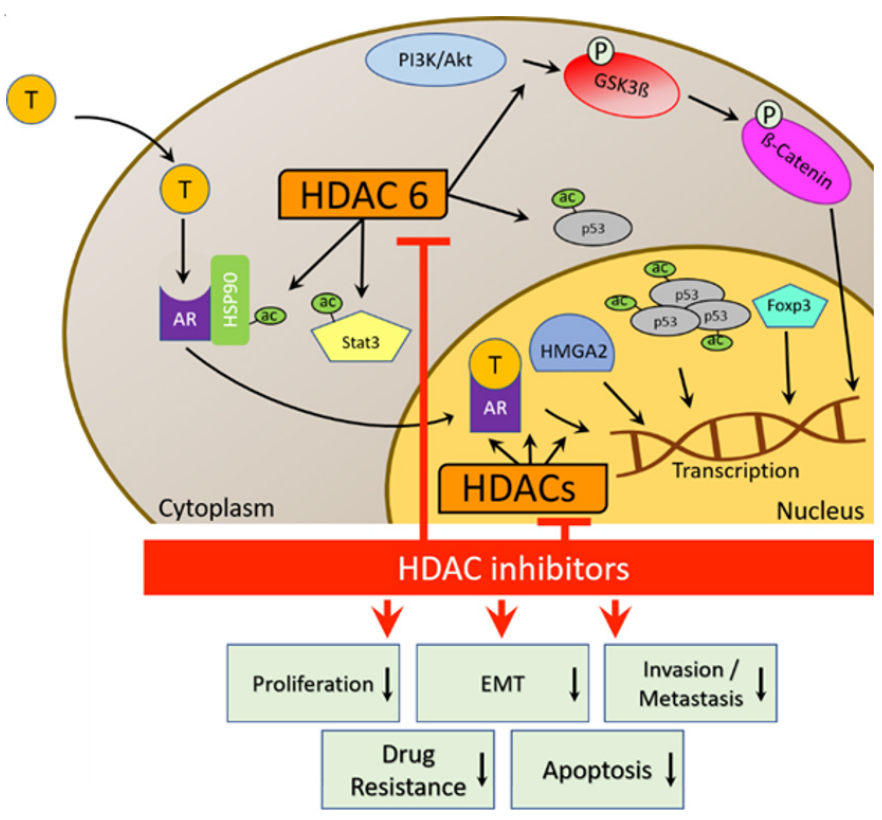

Figure 2. HDAC network and cellular effects of HDAC inhibitors in CRPC. HDAC: Histone deacetylase; HDACi: HDAC inhibitor; T: testosterone; Hsp90: heat shock protein 90; AR: androgen receptor; STAT3: signal transducer and activator of transcription 3; HMGA2: high mobility group AT-hook 2; EMT: epithelial-to-mesenchymal transition.

protein AR in LNCaP prostate cancer cells by an increase of acetylated Hsp9o levels accompanied by Hsp9o-AR dissociation and AR decomposition ${ }^{[42]}$.

Dacinostat also inactivated Akt by disruption of HDAC-PP1 (protein phosphatase 1) complexes, leading to the dephosphorylation of Akt proteins in PC3 prostate cancer cells $s^{[42]}$. Consequently, factors associated with Akt signaling were regulated by HDAC inhibitors. The Class I HDAC inhibitor entinostat $(5 \mathrm{mg} / \mathrm{kg} / \mathrm{day}, 5$ days per week, p.o.) augmented distinctly the anticancer activity of the survivin peptide vaccine SurVaxM as well as IFN $\gamma$ (interferon- $\gamma$ ) production in Myc-expressing CRPC mouse models (CR Myc-CaP). Entinostat upregulated acetyl-STAT3 accompanied by suppression of Foxp3 in cancer cells, which was suggested as its possible mode of action ${ }^{[43]}$. As part of its hormone-independent prostate cancer promoting effect, the natural HDAC inhibitor trichostatin A (TSA) increased the transcriptional activity of NF- $\kappa$ B in PC $3 \mathrm{M}$ 
prostate cancer cells associated with upregulation of fibrose growth factor $\mathrm{FGF}^{[44]}$. Thus, NF- $\mathrm{kB}$ suppressing agents might be promising combination partners of entinostat in terms of CRPC eradication. The PI3K/Akt signaling pathway is also involved in EMT induction ${ }^{[45]}$. EMT processes upregulate HMGA2. HMGA2 is a protein crucial for the regulation of gene expression by binding to AT-rich regions of DNA, which is the site where a replication complex is formed and the DNA synthesis is initiated. Interestingly, panobinostat was shown to suppress HMGA2 associated with reduced EMT formation and cell stemness. In addition, panobinostat increased the acetyl-p53 and acetyl-AR levels and prevented mCRPC formation in vivo at a dose of $10 \mathrm{mg} / \mathrm{kg}$ for five days per week $^{[46]}$. In terms of cancer stem cell markers, the HDAC inhibitors TSA and sodium butyrate upregulated the expression of the surface stem cell marker CD133 in prostate cancer derived primary epithelial cultures, which was based on chromatin relaxation leading to gene expression ${ }^{[47]}$.

\section{Promising combinations of HDAC inhibitors with anticancer drugs}

The detailed knowledge of the mechanisms of action of HDAC inhibitors in prostate cancers can be applied for combination therapies together with other suitable drugs against prostate cancer to achieve improved anticancer responses [Table 3, Figures 1 and 3]. DNA-based mechanisms appear to be promising drug targets for combination partners of HDAC inhibitors. Inhibition of DNA methylation was positively correlated with HDAC inhibition and sodium butyrate in combination with the DNA methyltransferase inhibitor 5-aza-2'-deoxycytidine significantly enhanced histone $\mathrm{H} 4$ acetylation and induced AR gene reexpression in androgen-independent DU145 prostate cancer cells. Moreover, it led to G2/M cell cycle arrest and reduced toxicity to non-malignant cells ${ }^{[48]}$. More recently, panobinostat was investigated in combination with the DNA methylation inhibitor hydralazine in various prostate cancer cells. The combination therapy was particularly active against androgen-independent DU145 prostate cancer cells, induced apoptosis, and reduced colony formation, invasion, and migration $^{[49]}$. Hence, the combination of panobinostat with hydralazine has the potential to block prostate cancer progression and might be a suitable therapy in future clinical studies.

Poly-ADP-ribosylpolymerase (PARP) is an enzyme involved in DNA repair. And the PARP inhibitor olaparib performed well in advanced clinical trials with CRPC patients who have a BRCA mutation, which led to the approval of olaparib for the treatment of BRCA-mutant prostate cancer ${ }^{[50,51]}$. The combination of vorinostat with olaparib synergistically reduced prostate cancer cell viability, induced apoptosis in DU 145 and $\mathrm{PC} 3$ prostate carcinoma cells, and suppressed DNA repair as well as DNA repair protein expression (BRCA1 and RAD51) in DU145 cells ${ }^{[52]}$. The combination of vorinostat with the PARP inhibitor veliparib also revealed synergistic effects on prostate cancer cell viability (in particular, on the viability of BRCA1mutant DU145 cells), apoptosis induction, DNA damage production, and BRCA1 suppression. The vorinostat/veliparib combination therapy suppressed BRCA1 by downregulation of the UHRF1 protein, which forms a stable DNA repair protein complex with BRCA1, and suppression of UHRF1 led to degradation of BRCA1 $1^{[53]}$. Thus, the combination of vorinostat with PARP inhibitors such as olaparib and veliparib appears to be a promising combination therapy for future clinical trials with CRPC patients.

Vorinostat was also studied in combination with the microtubule-stabilizing anticancer taxane drug docetaxel, and the combination showed synergistic growth inhibitory effects on 22Rv1 and VCaP CRPC cells. This combination therapy suppressed AR and $\mathrm{Bcl}-2$ expression, AR translocation into the prostate cancer cell nucleus, and AR signaling. The reduced accumulation of the AR in the nucleus was based on increased acetylation and bundling of tubulin in cells treated with the HDAC inhibitor vorinostat and the microtubule stabilizer docetaxel ${ }^{[54]}$. Another study targeting AR signaling comprised the combination treatment of androgen-accustomed DuCaP-N prostate cancer cells with the HDAC inhibitor TSA, the antiandrogen bicalutamide, and the $5 \alpha$-reductase inhibitor finasteride. The combination of TSA with 
Table 3. HDAC inhibitors in combination with other drugs against CRPC

\begin{tabular}{|c|c|c|}
\hline $\begin{array}{l}\text { HDAC } \\
\text { inhibitor }\end{array}$ & Combination partner (function) & Outcome \\
\hline $\begin{array}{l}\text { Sodium } \\
\text { butyrate }\end{array}$ & $\begin{array}{l}\text { 5-Aza-2'-deoxycytidine (DNA } \\
\text { methyltransferase inhibitor) }\end{array}$ & $\begin{array}{l}\text { Enhanced histone } \mathrm{H} 4 \text { acetylation, induced AR gene re-expression, G2/M cell cycle } \\
\text { arrest, reduced non-malignant cell toxicity }\end{array}$ \\
\hline Panobinostat ${ }^{[49]}$ & $\begin{array}{l}\text { Hydralazine (DNA methylation } \\
\text { inhibitor) }\end{array}$ & induced apoptosis, reduced colony formation, invasion, and migration \\
\hline Vorinostat $^{[52]}$ & Olaparib (PARP inhibitor) & $\begin{array}{l}\text { Synergistic reduction of cell viability, induced apoptosis, suppressed DNA repair, } \\
\text { BRCA1 and RAD51 expression downregulated }\end{array}$ \\
\hline Vorinostat ${ }^{[53]}$ & Veliparib (PARP inhibitor) & $\begin{array}{l}\text { Synergistic effects on cell viability (BRCA1-mutant DU145), apoptosis induction, DNA } \\
\text { damage production, BRCA1 suppression/degradation, suppressed UHRF1 }\end{array}$ \\
\hline Vorinostat $^{[54]}$ & Docetaxel (microtubules stabilizer) & $\begin{array}{l}\text { Increased tubulin acetylation and bundling, suppressed AR and Bcl-2 expression, } \\
\text { suppressed nuclear AR translocation and AR signaling }\end{array}$ \\
\hline Trichostatin $A^{[55]}$ & $\begin{array}{l}\text { Bicalutamide (anti-androgen) and } \\
\text { finasteride ( } 5 \alpha \text {-reductase inhibitor) }\end{array}$ & Synergistic apoptosis induction \\
\hline Panobinostat ${ }^{[57]}$ & Dovitinib (multi-RTK inhibitor) & No improved effects \\
\hline Ricolinostat $^{[58]}$ & $\begin{array}{l}\text { Selumetinib (MEK inhibitor) and } \\
\text { paclitaxel (microtubules stabilizer) }\end{array}$ & $\begin{array}{l}\text { Synergistic growth inhibition and apoptosis induction, suppression of KLK2 and DUSP1, } \\
\text { increased AR accumulation in cytoplasm }\end{array}$ \\
\hline $\begin{array}{l}\text { Valproic } \\
\text { acid }^{[62-64]}\end{array}$ & $\begin{array}{l}\text { Everolimus (mTOR inhibitor) and } \\
\text { IFN }\end{array}$ & $\begin{array}{l}\text { Increased cell growth inhibition, suppression of EGFR (epidermal growth factor } \\
\text { receptor), ERK1, and ERK2, increased acetyl-H3 }\end{array}$ \\
\hline Panobinostat ${ }^{[67]}$ & Everolimus (mTOR inhibitor) & $\begin{array}{l}\text { Myc-CaP cell growth inhibition, suppressed clonogenic survival and GO/G1 cell cycle } \\
\text { arrest, increased p } 21 \text { and p } 27 \text { expression; in vivo suppression of tumor growth, AR, } \\
\text { HIF-1 } \alpha \text {, miR-20a, miR-21 }\end{array}$ \\
\hline $\begin{array}{l}\text { Romidepsin, } \\
\text { Entinostat }^{[70]}\end{array}$ & Adenoviral TRAIL gene therapy & Restored CAR surface expression, augmented TRAIL-mediated caspase activity \\
\hline
\end{tabular}

PARP: Poly-ADP-ribosyl-polymerase; RTK: receptor tyrosine kinase; MEK: MAPK/ERK kinase; IFNa: interferon- $\alpha$; mTOR: mammalian target of rapamycin; EGFR: epidermal growth factor receptor; ERK: extracellular signal-regulated kinase; HIF: hypoxia inducible factor; miR: microRNA; CAR: coxsackie adenovirus receptor; TRAIL: TNF-related apoptosis-inducing ligand.

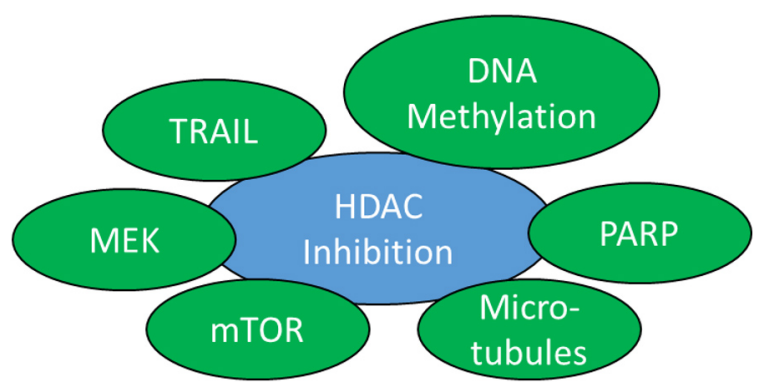

Figure 3. Suitable targets for combination therapies with HDAC inhibitors in CRPC. HDAC: Histone deacetylase; CRPC: castrationresistant prostate cancer; MEK: MAPK/ERK kinase; TRAIL: TNF-related apoptosis-inducing ligand.

bicalutamide and finasteride led to synergistic apoptosis induction in the DuCaP-N cells $s^{[55]}$.

Protein kinases are valuable targets for new anticancer drugs. Enhanced receptor tyrosine kinase (RTK) signaling was observed in advanced prostate cancers and appeared as a suitable drug target for targeted therapies ${ }^{[56]}$. Thus, the combination of HDAC inhibitors with TK inhibitors seems to be reasonable. However, the combination of the multi-RTK inhibitor dovitinib (TKI258) with panobinostat did not show improved anticancer effects on prostate cancer cells since dovitinib appeared to be particularly inactive in the tested prostate cancer cells ${ }^{[57]}$. MAPK/ERK kinase (MEK, a serine/threonine/tyrosine kinase) inhibitors suppress the Ras-MAPK signaling pathway in cancers, and a series of anticancer active MEK inhibitors was developed ${ }^{[58]}$. The MEK inhibitor selumetinib was studied in combination with the HDAC6 inhibitor ricolinostat in various CRPC cell lines (PC3, DU145, and 22Rv1). While the combination treatment revealed 
synergistic effects in all three cell lines, $22 \mathrm{Rv} 1$ cells were particularly sensitive in terms of growth inhibition. A suppression of the AR target genes KLK2 and DUSP1 was observed in treated 22Rv1 cells as well as increased AR accumulation in the cytoplasm. Addition of the taxane paclitaxel to the ricolinostat/selumetinib combination led to synergistic growth inhibition and increased apoptosis induction in all three prostate cancer cell lines, which coincides well with the aforementioned anti-prostate cancer effects of the combined vorinostat/docetaxel treatment ${ }^{[59]}$.

Akt and its downstream factor mTOR (mammalian target of rapamycin) are well established anticancer targets of the phosphatidylinositol 3-kinase (PI3K) signaling pathway ${ }^{[60]}$. Various mTOR inhibitors such as rapamycin, everolimus, and temsirolimus were developed and approved by the FDA ${ }^{[61]}$. The anticancer activities comprising inhibition of prostate cancer cell growth, migration, and invasion of HDAC inhibitors such as valproic acid were increased when combined with everolimus ${ }^{[62,63]}$. Furthermore, the activity of valproic acid plus everolimus was augmented by addition of low-dose interferon- $\alpha$ (IFN $\alpha$ ), and this tripledrug therapy was superior to single-drug therapy in terms of prostate tumor cell growth inhibition and dissemination. Intracellular signaling of PC3 cells was downregulated based on suppression of EGFR (epidermal growth factor receptor), ERK1, and ERK2, while acetyl-H3 levels were increased in treated cells ${ }^{[64]}$. Panobinostat was also studied in combination with everolimus in prostate cancer. For this reason, the $c$-Myc expressing Myc-CaP prostate cancer cell line was applied because c-Myc expression reduced the activity of the mTOR inhibitor rapamycin in prostate cancer ${ }^{[6,666]}$. The combination of panobinostat with everolimus exhibited significant Myc-CaP cell growth inhibition, while the combined treatment of Myc$\mathrm{CaP}$ cells at non-cytotoxic doses of $10 \mathrm{nM}$ for each compound suppressed clonogenic survival and induced Go/G1 cell cycle arrest associated with increased expression of the cyclin-dependent kinase inhibitors p21 and p27. In addition, combined panobinostat $(10 \mathrm{mg} / \mathrm{kg}$, i.p.) and everolimus (10 mg/kg, p.o.) treatment for 15 days (QD $\times 7$ schedule) showed reduction of tumor proliferation and tumor volume in mice bearing androgen-sensitive as well as castration-resistant Myc-CaP tumors. The combination treatment blocked AR and HIF- $1 \alpha$ transcriptional activities both in vitro and in vivo and downregulated the oncogenic microRNAs (oncomirs) miR-20a and miR-21 in vivo, which were associated with AR/hypoxia and $c$-Myc/hypoxia signaling pathways ${ }^{[67]}$.

Virus therapies have become interesting tools for gene therapies of tumor diseases and adenoviral TRAIL gene therapy caused signs of apoptosis in the examined prostates of prostate cancer patients ${ }^{[68]}$. Since gene suppression in cancer cells can be reversed by HDAC inhibitors, the combination of gene therapy with HDAC inhibitors seems to be feasible. The HDAC inhibitors romidepsin and MS-275 increased the effects of adenoviral TRAIL gene therapy on castration-sensitive LNCaP prostate cancer cells without toxicity to non-malignant prostate epithelial cells ${ }^{[6]]}$. Based on this finding, the combination of TRAIL gene therapy with romidepsin or MS-275 in C4-2B CRPC cells was studied. Decreased coxsackie and adenovirus receptor (CAR) expression was correlated with increased tumorigenicity and metastasis formation in the LNCaPderived human prostate cancer subline $\mathrm{C} 4-2 \mathrm{~B}$, however, both aforementioned HDAC inhibitors restored CAR surface expression and augmented TRAIL-mediated caspase activity based on enhanced adenoviral transduction efficacy when combined with TRAIL gene therapy ${ }^{[70]}$.

\section{New HDAC inhibitors}

Aside from combination of approved HDAC inhibitors with other anticancer drugs, the development of new HDAC inhibitors with improved anticancer properties turned out to be a reasonable strategy to tackle CRPC [Table 4, Figure 4]. 
Table 4. New HDAC inhibitors with promising anti-CRPC activities

\begin{tabular}{|c|c|c|c|}
\hline Compd. & Structural motif(s) & In vitro activity & In vivo activity \\
\hline $\mathrm{CN}_{133^{[71]}}$ & Hydroxamic acid, adamantyl cap & $\begin{array}{l}\text { Inhibition of HDAC1-3; } 100 \text { times more active than SAHA (22Rv1 cells), inhibition of cell migration, } \\
\text { invasion and AR signaling }\end{array}$ & $\begin{array}{l}\text { Tumor growth and weight reduction by } 50 \% \\
(22 R v 1)\end{array}$ \\
\hline $2-75^{[74,75]}$ & $\begin{array}{l}\text { Hydroxamic acid, AR-targeting } \\
\text { enzalutamide-type cap }\end{array}$ & $\begin{array}{l}\text { HDAC inhibitory activity, induced p21, higher acetyl-tubulin levels (based on stronger HDAC6 } \\
\text { inhibition) than SAHA, suppressed Hsp90 and AR/AR-V7 }\end{array}$ & $\begin{array}{l}\text { Improved long-term tumor growth inhibition, } \\
\text { enhanced apoptosis, reduced nuclear AR } \\
\text { accumulation (LNCaP) }\end{array}$ \\
\hline CUDC- $101^{[77]}$ & $\begin{array}{l}\text { Hydroxamic acid, EGFR/HER2-targeting } \\
\text { erlotinib-type anilinoquinazoline cap }\end{array}$ & Suppressed AR, AR-V7, and HER2 & $\begin{array}{l}\text { Significant tumor growth inhibition without } \\
\text { weight loss ( } 22 \mathrm{Rv} 1 \text { ) }\end{array}$ \\
\hline $\begin{array}{l}\text { 3ClQuin-SAHA } \\
\text { 3BrQuin-SAHA }\end{array}$ & $\begin{array}{l}\text { Hydroxamic acid, EGFR-targeting } \\
\text { gefitinib-type anilinoquinazoline cap }\end{array}$ & $\begin{array}{l}\text { Higher antiproliferative activity than gefitinib (DU145 cells), HDAC inhibition, EGFR inhibition, } \\
\text { mTOR suppression }\end{array}$ & - \\
\hline $\begin{array}{l}\text { CUDC-907 } \\
\text { (fimepino-stat) }^{[86]}\end{array}$ & $\begin{array}{l}\text { Hydroxamic acid, PI3K-targeting } \\
\text { thienopyrimidine cap }\end{array}$ & $\begin{array}{l}\text { High growth inhibitory activity, inhibition of HDACs and PI3K, apoptosis induction, increased Bim, } \\
\text { suppressed Mcl-1 and Bcl-xL, suppressed DNA repair and DNA damage response proteins (Wee1, } \\
\text { CHK1, RRM1, and RRM2), suppressed c-Myc }\end{array}$ & $\begin{array}{l}\text { Tumor growth inhibition by } 60 \% \text { without weight } \\
\text { loss (LuCaP 35CR patient-derived mouse } \\
\text { xenografts) }\end{array}$ \\
\hline
\end{tabular}

AR: Androgen receptor; EGFR: epidermal growth factor receptor; HER2: human epidermal growth factor receptor 2; mTOR: mammalian target of rapamycin; PI3K: phosphatidylinositol 3-kinase.

The adamantyl-capped HDAC inhibitor $\mathrm{CN}_{13} 3$ was superior to vorinostat in terms of Class I HDAC1, -2 , and -3 inhibition $\left(\mathrm{IC}_{50}=0.6,2\right.$, and $0.3 \mathrm{nM}$ for $\mathrm{CN} 133 ; 4,11$, and $3 \mathrm{nM}$ for vorinostat), while vorinostat was more active against $\mathrm{HDAC} 6\left(\mathrm{IC}_{50}=2 \mathrm{nM}\right)$ than $\mathrm{CN} 133\left(\mathrm{IC}_{50}=4.1 \mathrm{nM}\right)$. CN133 was 100 times higher antiproliferative $\left(\mathrm{IC}_{50}=10 \mathrm{nM}\right)$ in $22 \mathrm{Rv} 1 \mathrm{CRPC}$ cells than vorinostat $\left(\mathrm{IC}_{50}=1 \mu \mathrm{M}\right)$. CN133 inhibited CRPC cell migration and invasion and suppressed AR signaling. Mice bearing 22Rv1 CRPC were treated with CN133 (1 mg/kg), which reduced tumor volume and tumor weight by 50\% in comparison with placebo group mice $e^{[7] 1}$.

Hybrid molecules targeting two or more anticancer targets can possess higher anticancer activities accompanied by reduced drug-drug interactions and less complex pharmacokinetic ${ }^{[72,73]}$. Several chimeric HDAC inhibitors with dual or multimodal activities were reported over the last years ${ }^{[2,30]}$. Compound $2-75$ is a promising enzalutamide hybrid with HDAC inhibitory activity, which induced p21, led to higher acetyl-tubulin levels (based on stronger HDAC6 inhibition) than vorinostat, and suppressed Hsp90 and AR protein levels in C4-2 prostate cancer cells $\mathrm{s}^{[74]}$. Based on these results, deeper studies of 2-75 in CRPC were carried out. Compound 2-75 suppressed DHT-induced AR transcriptional activity and AR translocation to the nucleus stronger than enzalutamide. In addition to AR, the mutant AR-V7 was also downregulated by 2-75 in prostate cancer cells in a proteasome-dependent way, indicating enhanced AR degradation in 2-75-treated cells. In vivo experiments with LNCaP tumor models revealed that 2-75 treatment (10 mg/kg, intratumoral injection twice weekly) had tumor growth inhibitory activity similar to enzalutamide, but, in the long run (after Day 24), 2-75 displayed improved tumor growth inhibition when compared with enzalutamide. The in vivo activity of 2-75 was accompanied by increased apoptosis induction and suppressed AR nuclear accumulation in the tumor bodies of treated mice ${ }^{[75]}$. 
<smiles>CN(Cc1ccc(/C=C/C(=O)NO)cc1)CC12CC3CC(CC(C3)C1)C2</smiles><smiles>C#Cc1cccc(Nc2ncnc3cc(OC)c(OCCCCCCC(=O)NO)cc23)c1</smiles>

CUDC-101<smiles>[X]c1cccc(Nc2ncnc3ccc(NC(=O)CCCCCCC(=O)NO)cc23)c1</smiles>

3ClQuin-SAHA $(\mathrm{R}=\mathrm{Cl})$ 3BrQuin-SAHA $(\mathrm{R}=\mathrm{Br})$

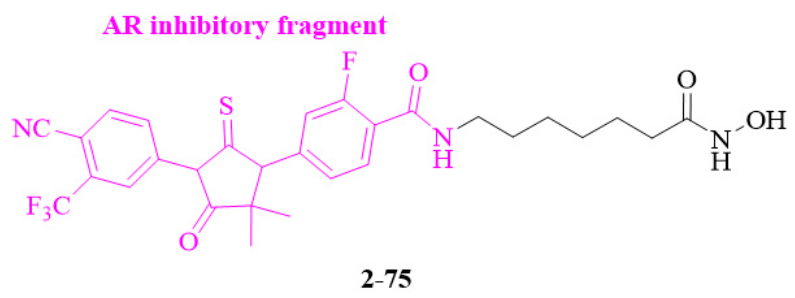

$2-75$
PI3K-inhibitory fragment<smiles>COc1ccc(-c2nc(N3CCOCC3)c3sc(CN(C)c4ncc(C(=O)NO)cn4)cc3n2)cn1</smiles>

Figure 4. Structures of new HDAC inhibitors with promising activities against CRPC. HDAC: Histone deacetylase; CRPC: castrationresistant prostate cancer; AR: androgen receptor; EGFR: epidermal growth factor receptor; PI3K: phosphatidylinositol 3-kinase.

The aforementioned receptor tyrosine kinases such as EGFR are excellent targets for the design of new HDAC/EGFR inhibitors. Compound CUDC-101 combines an HDAC inhibitory fragment with an EGFR inhibitory scaffold derived from the approved anticancer active EGFR inhibitor erlotinib and inhibited HDAC, EGFR, and HER2 ${ }^{[76]}$. In CRPC cells, CUDC-101 suppressed full-length AR as well as the variant AR form $\mathrm{AR}-\mathrm{V} 7$, upregulated $\mathrm{p} 21$, and downregulated HER2/NEU. In castrated mice bearing aggressive 22Rv1 CRPC tumors, CUDC-101 (50 $\mu \mathrm{g} / \mathrm{kg} /$ day for 14 days $)$ inhibited tumor growth significantly without measurable weight loss of treated mice ${ }^{[77]}$.

Erlotinib and CUDC-101 have certain drawbacks, which warranted further research efforts. The ethinylphenyl residue of erlotinib can be activated by cytochrome P450 enzymes leading to oxidized phenol and quinone compounds with certain toxicity potential ${ }^{[78]}$. Indeed, erlotinib was reported to increase the risk of lethal gastrointestinal tract perforations in cancer patients taking corticosteroids or ciprofloxacin ${ }^{[79]}$. A clinical phase 1 study of CUDC-101 together with chemoradiation in head and neck squamous cell carcinoma (HNSCC) patients reported that five out of twelve HNSCC patients (i.e., 41\%) had to stop the therapy due to adverse events ${ }^{[80]}$. In addition, CUDC-101 was shown to be a substrate of the cell-detoxifying $\mathrm{ABC}$ transporters $\mathrm{ABCB} 1$ (P-gp) and $\mathrm{ABCG} 2$ (BCRP) leading to resistance to CUDC-101 treatment, whereupon the combination with P-gp and/or BCRP inhibitors was suggested in order to avoid CUDC-101 resistance formation ${ }^{[81]}$. In contrast to that, the approved EGFR inhibitor gefitinib reversed P-gp- and BCRP-mediated drug resistance in vitro and in viv ${ }^{[82,83]}$. Hence, gefitinib is a promising conjugation partner, and chimeric HDAC inhibitors with gefitinib-derived cap scaffolds based on halogen-substituted aniline rings were prepared. The chimeric compounds 3ClQuin-SAHA and 3BrQuin-SAHA showed 3-4 times higher growth inhibitory activity $\left(\mathrm{IC}_{50}=3.23 \mu \mathrm{M}\right.$ for $3 \mathrm{ClQ}$ uin-SAHA and $3.53 \mu \mathrm{M}$ for 3 BrQuin-SAHA) 
against DU145 CRPC cells than gefitinib $\left(\mathrm{IC}_{50}=11.9 \mu \mathrm{M}\right)$; however, vorinostat $\left(\mathrm{IC}_{50}=0.68 \mu \mathrm{M}\right)$ was still more antiproliferative in these prostate cancer cells. Nevertheless, 3ClQuin-SAHA and 3BrQuin-SAHA combined EGFR inhibitory activity with HDAC inhibition, suppressed EGFR expression comparable to vorinostat, showed only marginal unspecific toxicities, induced apoptosis in DU145 cells, and inhibited angiogenesis ${ }^{[84]}$. Hence, these chimeric compounds can be suitable anticancer drug candidates in prostate cancer therapy in terms of reduced erlotinib (and vorinostat) toxicity and resistance formation.

CUDC-907 (fimepinostat) is another promising HDAC/kinase inhibitor, which was designed to target HDAC enzymes and the kinase PI3 $\mathrm{K}^{[85]}$. Based on previous reports describing the synergistic effects of CUDC-907 in various cancer models and since PI3K signaling also plays an eminent role for CRPC development (see the aforementioned role of MTOR inhibitors), CUDC-907 was investigated in prostate cancer models. CUDC-907 showed excellent growth inhibitory activities in a panel of eight prostate cancer cell lines with $\mathrm{IC}_{50}$ values between 2 and $17.4 \mathrm{nM}$, inhibited HDACs and PI3K signaling, and induced apoptosis in a dose-dependent way associated with increased pro-apoptotic Bim and suppressed antiapoptotic Mcl-1 and Bcl-xL expression in 22Rv1 CRPC cells. In addition, CUDC-907 treatment led to enhanced DNA damage due to downregulated DNA damage response proteins (Wee1, CHK1, RRM1, and $\mathrm{RRM} 2$ ). The protein expression of the oncoprotein $c$-Myc, which regulates the mentioned apoptosis factors and DNA damage response proteins, was also suppressed by CUDC-907 and, thus, $c$-Myc suppression plays a key role in the anti-prostate cancer mode of action of CUDC-907. Finally, CUDC-907 (100 mg/kg/day, p.o.) was tested in castration-resistant $\mathrm{LuCaP} 35 \mathrm{CR}$ mouse xenografts and inhibited in vivo tumor growth by ca. $60 \%$ while no weight loss was detected ${ }^{[86]}$. More recently, a phase 2 study of oral CUDC-907 for the treatment of relapsed/refractory diffuse large and high-grade B-cell lymphoma (DLBCL and HGBL) patients with enhanced Myc-expression and/or altered MYC gene constitutions (e.g., altered gene composition by translocation) was published revealing an overall response rate of $22 \%$ in the MYC-altered disease patients ${ }^{[87]}$. Hence, patients enrolled for future prostate cancer clinical studies with oral CUDC-907 should be tested for their MYC-status. In contrast to CUDC-101, CUDC-907 was not a substrate of P-gp $(\mathrm{ABCB} 1)$ transporters, and its antiproliferative activity was conserved in P-gp-expressing tumor cells. However, CUDC-907 was still efficiently inactivated by BRCP (ABCG2) transporters, similar to CUDC-101, and combinations with BCRP inhibitors were recommended to keep the high anticancer activity of CUDC$907^{[88]}$.

\section{CONCLUSION}

HDAC inhibitors exhibit reasonable in vitro and in vivo activities against CRPC. Clinical trials have shown that monotherapy with HDAC inhibitors cannot be recommended now for phase 3 studies due to low efficacy and considerable toxicity in CRPC patients. However, the combination of HDAC inhibitors with certain anticancer drugs such as taxanes and anti-androgens appeared promising based on the data from clinical studies. In preclinical studies, DNA methylation inhibitors, PARP inhibitors, various protein kinase and MTOR inhibitors, interferon, and TRAIL gene therapy appeared to be suitable combination partners for HDAC inhibitors, which should be considered for future clinical studies with CRPC patients.

Various new HDAC inhibitors have emerged over the last years, which displayed significant activity against CRPC in preclinical studies. Many of these new HDAC inhibitors were designed to target non-HDAC proteins such as protein kinases or the AR in addition to HDAC enzymes. Among them, CUDC-101 and CUDC-907, which are HDAC/kinase inhibitors, are striking examples that have already entered clinical trials. The activities of these two drug candidates were thoroughly studied in preclinical CRPC models giving hints at strengths and weaknesses of multi-targeting HDAC inhibitors. Strong CRPC growth inhibition accompanied by good drug tolerance in mice were contrasted by toxicity in patients and 
resistance formation based on the expression of $\mathrm{ABC}$ transporters in tumor cells. Efforts to eliminate the drawbacks of CUDC-101 and CUDC-907 are already in progress and the first preclinical results of new $\mathrm{HDAC} /$ kinase inhibitory derivatives are available. In addition, subgroups of CRPC patients with increased Myc levels should be considered for future clinical trials with CUDC-907 since lymphoma patients with elevated Myc responded well to this sophisticated HDAC inhibitor.

The drug developments described in this work are based on the elucidation of the mechanisms of action of first-generation HDAC inhibitors, the design of new therapy regimens, and the synthesis of new HDAC inhibitors with improved anticancer properties. The close interplay of clinicians, tumor biologists, and synthetic chemists has led to promising outcomes in the field of CRPC research over the last years, and interdisciplinary work will continue to help HDAC inhibitor-based therapy to play a prominent role as efficient and well-tolerated CRPC treatment in the future.

\section{DECLARATIONS}

\section{Authors' contributions}

Made substantial contributions to conception and design of the study, provided administrative and technical support: Nitzsche B, Höpfner M

Performed data acquisition, data analysis and interpretation: Biersack B

\section{Availability of data and materials}

Not applicable.

\section{Financial support and sponsorship}

None.

\section{Conflicts of interest}

All authors declared that there are no conflicts of interest.

\section{Ethical approval and consent to participate}

Not applicable.

\section{Consent for publication}

Not applicable.

\section{Copyright}

(c) The Author(s) 2022.

\section{REFERENCES}

1. Rawla P. Epidemiology of prostate cancer. World J Oncol 2019;10:63-89. DOI PubMed PMC

2. Damodaran S, Kyriakopoulos CE, Jarrard DF. Newly diagnosed metastatic prostate cancer: has the paradigm changed? Urol Clin North Am 2017;44:611-21. DOI PubMed PMC

3. Sartor AO. Progression of metastatic castrate-resistant prostate cancer: impact of therapeutic intervention in the post-docetaxel space. $J$ Hematol Oncol 2011;4:18. DOI PubMed PMC

4. Hellerstedt B, Pienta K. The current state of hormonal therapy for prostate cancer. CA Cancer J Clin 2008;52:154-79. DOI PubMed

5. Smith MR, Saad F, Chowdhury S, et al. Apalutamide treatment and metastasis-free survival in prostate cancer. $N$ Engl $J$ Med 2018;378:1408-18. DOI PubMed

6. Hussain M, Fizazi K, Saad F, et al. Enzalutamide in men with nonmetastatic, castration-resistant prostate cancer. $N$ Engl J Med 2018;378:2465-74. DOI PubMed PMC

7. Fizazi K, Shore N, Tammela TL, et al. Darolutamide in nonmetastatic, castration-resistant prostate cancer. $N$ Engl J Med 2019;380:1235-46. DOI PubMed

8. Leung DK, Chiu PK, Ng C, Teoh JY. Novel strategies for treating castration-resistant prostate cancer. Biomedicines 2021;9:339. DOI PubMed PMC 
9. Scott LJ. Abiraterone acetate: a review in metastatic castration-resistant prostrate cancer. Drugs 2017;77:1565-76. DOI PubMed

10. Kornberg RD. Chromatin structure: a repeating unit of histone and DNA. Science 1974;184:868-71. DOI PubMed

11. Kornberg RD. Structure of chromatin. Annu Rev Biochem 1977;46:931-54. DOI PubMed

12. Ropero S, Esteller M. The role of histone deacetylases (HDACs) in human cancer. Mol Oncol 2007;1:19-25. DOI PubMed PMC

13. New M, Olzscha H, La Thangue NB. HDAC inhibitor-based therapies: can we interpret the code. Mol Oncol 2012;6:637-56. DOI PubMed PMC

14. Singh BN, Zhang G, Hwa YL, Li J, Dowdy SC, Jiang SW. Nonhistone protein acetylation as cancer therapy targets. Expert Rev Anticancer Ther 2010;10:935-54. DOI PubMed PMC

15. Abbas A, Gupta S. The role of histone deacetylases in prostate cancer. Epigenetics 2008;3:300-9. DOI PubMed PMC

16. Conteduca V, Hess J, Yamada Y, Ku SY, Beltran H. Epigenetics in prostate cancer: clinical implications. Trans Androl Urol 2021;10:3104-16. DOI PubMed PMC

17. Crea F, Sun L, Mai A, et al. The emerging role of histone lysine demethylases in prostate cancer. Mol Cancer 2012;11:52. DOI PubMed PMC

18. Huang $\mathrm{PH}, \mathrm{Chen} \mathrm{CH}$, Chou CC, et al. Histone deacetylase inhibitors stimulate histone H3 lysine 4 methylation in part via transcriptional repression of histone H3 lysine 4 demethylases. Mol Pharmacol 2011;79:197-206. DOI PubMed PMC

19. Orzan F, Pellegatta S, Pollani PL, et al. Enhancer of Zeste 2 (EZH2) is up-regulated in malignant gliomas and in glioma stem-like cells. Neuropathol Appl Neurobiol 2011;37:381-394. DOI PubMed

20. Nebbioso A, Carafa V, Benedetti R, Altuicci L. Trials with "epigenetic" drugs: an update. Mol Oncol 2012;6:657-82. DOI PubMed PMC

21. Halkidou K, Gaughan L, Cook S, Leung HY, Neal DE, Robson CN. Upregulation and nuclear recruitment of HDAC1 in hormone refractory prostate cancer. Prostate 2004;59:177-89. DOI PubMed

22. Weichert W, Röske A, Gekeler V, et al. Histone deacetylases 1, 2, and 3 are highly expressed in prostate cancer and HDAC2 expression is associated with shorter PSA relapse time after radical prostatectomy. Br J Cancer 2008;98:604-10. DOI PubMed PMC

23. Welsbie DS, Xu J, Chen Y, et al. Histone deacetylases are required for androgen receptor function in hormone-sensitive and castrateresistant prostate cancer. Cancer Res 2009;69:958-66. DOI PubMed PMC

24. Rana Z, Diermeier S, Hanif M, Rosengren RJ. Understanding failure and improving treatment using HDAC inhibitors for prostate cancer. Biomedicines 2020;8:22. DOI PubMed PMC

25. Kong D, Ahmad A, Bao B, Li Y, Banerjee S, Sarkar FH. Histone deacetylase inhibitors induce epithelial-to-mesenchymal transition in prostate cancer cells. PLoS ONE 2012;7:e45045. DOI PubMed PMC

26. Ververis K, Hiong A, Karagiannis TC, Licciardi PV. Histone deacetylase inhibitors (HDACIs): multitargeted anticancer agents. Biologics 2013;7:47-60. DOI PubMed PMC

27. Gregoretti IV, Lee YM, Goodson HV. Molecular evolution of the histone deacetylase family: functional implications of phylogenetic analysis. J Mol Biol 2004;338:17-31. DOI PubMed

28. Paris M, Porcelloni M, Binaschi M, Fattori D. Histone deacetylase inhibitors: from bench to bedside. J Med Chem 2008;51:1505-29. DOI PubMed

29. Schobert R, Biersack B. Multimodal HDAC inhibitors with improved anticancer activity. Curr Cancer Drug Targets 2018;18:39-56. DOI PubMed

30. Biersack B, Polat S, Höpfner M. Anticancer properties of chimeric HDAC and kinase inhibitors. Semin Cancer Biol 2020. DOI PubMed

31. Kaushik D, Vashistha V, Isharwal S, Sediqe SA, Lin MF. Histone deacetylase inhibitors in castration-resistant prostate cancer: molecular mechanism of action and recent clinical trials. Ther Adv Urol 2015;7:388-95. DOI PubMed PMC

32. Molife LR, Attard G, Fong PC, et al. Phase II, two-stage, single-arm trial of the histone deacetylase inhibitor (HDACi) romidepsin in metastatic castration-resistant prostate cancer (CRPC). Ann Oncol 2010;21:109-13. DOI PubMed

33. Bradley D, Rathkopf D, Dunn R, et al. Vorinostat in advanced prostate cancer patients progressing on prior chemotherapy (National Cancer Institute Trial 6862): trial results and interleukin-6 analysis: a study by the Department of Defense Prostate Cancer Clinical Trial Consortium and University of Chicago Phase 2 Consortium. Cancer 2009;115:5541-9. DOI PubMed PMC

34. Rathkopf D, Picus J, Hussain A, et al. A phase 2 study of intravenous panobinostat in patients with castration-resistant prostate cancer. Cancer Chemother Pharmacol 2013;72:537-44. DOI PubMed PMC

35. Rathkopf D, Wong B, Ross R, et al. A phase I study of oral panobinostat (LBH589) alone and in combination with docetaxel (Doc) and prednisone in castration-resistant prostate cancer (CRPC). J Clin Oncol 2008;26:5152. DOI

36. Ferrari A, Stein M, Alumkal, et al. A phase I/II randomized study of panobinostat and bicalutamide in castration-resistant prostate cancer (CRPC) patients progressing on second-line hormone therapy. J Clin Oncol 2011;29:156. DOI

37. Ferrari AC, Alumkal JJ, Stein MN, et al. Epigenetic therapy with panobinostat combined with bicalutamide rechallenge in castrationresistant prostate cancer. Clin Cancer Res 2019;25:52-63. DOI PubMed

38. Eigl BJ, North S, Winquist, et al. A phase II study of the HDAC inhibitor SB939 in patients with castration resistant prostate cancer: NCIC clinical trials group study IND195. Invest New Drugs 2015;33:969-76. DOI PubMed

39. Tang S, Lian X, Jiang J, et al. Tumor suppressive maspin-sensitized prostate cancer to drug treatment through negative regulating androgen receptor expression. Front Cell Dev Biol 2020;8:573820. DOI PubMed PMC

40. Fang Y, Fliss A, Robins D, Caplan A. Hsp90 regulates androgen receptor hormone binding affinity in vivo. J Biol Chem 1996;271:28697-702. DOI PubMed

41. Gravina GL, Marampon F, Muzi P, et al. PXD101 potentiates hormonal therapy and prevents the onset of castration-resistant 
phenotype modulating androgen receptor, Hsp90, and CRM1 in preclinical models of prostate cancer. Endocr Relat Cancer 2013;20:321-37. DOI PubMed

42. Chen L, Meng S, Wang H, et al. Chemical ablation of androgen receptor in prostate cancer cells by the histone deacetylase inhibitor LAQ824. Mol Cancer Ther 2005;4:1311-9. DOI PubMed

43. Shen L, Ciesilski M, Ramakrishnan S, et al. Class I histone deacetylase inhibitor entinostat suppresses regulatory T cells and enhances immunotherapies in renal and prostate cancer models. PLoS One 2012;7:e30815. DOI PubMed PMC

44. Armstrong K, Robson CN, Leung HY. NF- $\mathrm{kB}$ activation upregulates fibroblast growth factor 8 expression in prostate cancer cells. Prostate 2006;66:1223-34. DOI PubMed

45. Xu W, Yang Z, Lu N. A new role for the PI3K/Akt signaling pathway in the epithelial-mesenchymal transition. Cell Adh Migr 2015;9:317-24. DOI PubMed PMC

46. Ruscetti M, Dadashian E, Guo W, et al. HDAC inhibition impedes epithelial-mesenchymal plasticity and suppresses metastatic, castration-resistant prostate cancer. Oncogene 2016;35:3781-95. DOI PubMed PMC

47. Pellacani D, Packer RJ, Frame FM, et al. Regulation of the stem cell marker CD133 is independent of promoter hypermethylation in human epithelial differentiation and cancer. Mol Cancer 2011;10:94. DOI PubMed PMC

48. Fialova B, Luzna P, Gursky J, Langova K, Kolar Z, Trtkova KS. Epigenetic modulation of AR expression in prostate cancer DU145 cells with the combination of sodium butyrate and 5'-aza-2'-deoxycytidine. Oncol Rep 2016;36:2365-74. DOI PubMed

49. Pacheco MB, Camilo V, Lopes N, et al. Hydralazine and panobinostat attenuate malignant properties of prostate cancer cell lines. Pharmaceuticals 2021;14:670. DOI PubMed PMC

50. Felice F, Tombolini V, Marampon F, Musella A, Marchetti C. Defective DNA repair mechanisms in prostate cancer: impact of olaparib. Drug Des Devel Ther 2017;11:547-52. DOI PubMed PMC

51. Martin GA, Chen AH, Parikh K. A novel use of olaparib for the treatment of metastatic castration-recurrent prostate cancer. Pharmacotherapy 2017;37:1406-14. DOI PubMed

52. Chao OS, Goodman Jr OB. Synergistic loss of prostate cancer cell viability by coinhibition of HDAC and PARP. Mol Cancer Res 2014;12:1755-66. DOI PubMed

53. Yin L, Liu Y, Peng Y, et al. PARP inhibitor veliparib and HDAC inhibitor SAHA synergistically co-target the UHRF1/BRCA1 DNA damage repair complex in prostate cancer cells. J Exp Clin Cancer Res 2018;37:153. DOI PubMed PMC

54. Park SE, Kim H-G, Kim DE, et al. Combination treatment with docetaxel and histone deacetylase inhibitors downregulates androgen receptor signalin in castration-resistant prostate cancer. Invest New Drugs 2018;36:195-205. DOI

55. Pfeiffer MJ, Mulders PF, Schalken JA. An in vitro model for preclinical testing of endocrine therapy combinations for prostate cancer. Prostate 2010;70:1524-32. DOI PubMed

56. Drake JM, Graham NA, Stoyanova T, et al. Oncogene-specific activation of tyrosine kinase networks during prostate cancer progression. Proc Natl Acad Sci U S A 2012;109:1643-8. DOI PubMed PMC

57. Vallo S, Mani J, Stastny M, et al. The prostate cancer blocking potential of the histone deacetylase inhibitor LBH598 is not enhanced by the multi receptor tyrosine kinase inhibitor TKI258. Invest New Drugs 2013;31:265-72. DOI

58. Cheng Y, Tian H. Current development status of MEK inhibitors. Molecules 2017;22:1551. DOI PubMed PMC

59. Corno C, Arrighetti N, Ciusani E, et al. Synergistic interaction of histone deacetylase 6- and MEK-inhibitors in castration resistant prostate cancer cells. Front Cell Dev Biol 2020;8:610. DOI PubMed PMC

60. Sabatini DM. mTOR and cancer: insights into a complex relationship. Nat Rev Cancer 2006;6:729-34. DOI PubMed

61. Sawyers CL. Will mTOR inhibitors make it as cancer drugs? Cancer Cell 2003;4:343-8. DOI PubMed

62. Wedel S, Hudak L, Seibel JM, et al. Inhibitory effects of the HDAC inhibitor valproic acidon prostate cancer growth are enhanced by simultaneous application of the mTOR inhibitor RAD001. Life Sci 2011;88:418-24. DOI PubMed

63. Wedel S, Hudak L, Seibel JM, et al. Impact of combined HDAC and mTOR inhibition on adhesion, migration and invasion of prostate cancer cells. Clin Exp Metastasis 2011;28:479-91. DOI PubMed

64. Tsaur I, Hudak L, Makarevic J, et al. Intensified antineoplastic effect by combining an HDAC-inhibitor, an mTOR-inhibitor and low dose interferon alpha in prostate cancer cells. J Cell Mol Med 2015;19:1795-804. DOI

65. Ellis L, Lehet K, Ramakrishnan S, et al. Concurrent HDAC and mTORC1 inhibition attenuate androgen receptor and hypoxia signaling associated with alterations in microRNA expression. PLoS ONE 2011;6:e27178. DOI PubMed PMC

66. Ellwood-Yen K, Graeber TG, Wongvipat J, et al. Myc-driven murine prostate cancer shares molecular features with human prostate tumors. Cancer Cell 2003;4:223-38. DOI PubMed

67. Balakumaran BS, Porrello A, Hsu DS, et al. MYC activity mitigates response to rapamycin in prostate cancer through eukaryotic initiation factor 4E-binding protein 1-mediated inhibition of autophagy. Cancer Res 2009;69:7803-10. DOI PubMed PMC

68. Holoch PA, Griffith TS. TNF-related apoptosis-inducing ligand (TRAIL): a new path to anti-cancer therapies. Eur J Pharmacol 2009;625:63-72. DOI PubMed PMC

69. Kasman L, Lu P, Voelkel-Johnson C. The histone deacetylase inhibitors depsipeptide and MS-275, enhance TRIL gene therapy of LNCaP prostate cancer cells without adverse effects in normal prostate epithelial cells. Cancer Gene Ther 2007;14:327-34. DOI

70. Kasman L, Oicescu G, Voelkel-Johnson C. Histone deacetylase inhibitors restore cell surface expression of the Coxsackie adenovirus receptor and enhance CMV promoter activity in castration-resistant prostate cancer cells. Prostate Cancer 2012;2012:137163. DOI PubMed PMC

71. Chen Z, Wang X, Yang X, et al. Imaging assisted evaluation of antitumor efficacy of a new histone deacetylase inhibitor in the castration-resistant prostate cancer. Eur J Nucl Med Mol Imaging 2021;48:53-66. DOI PubMed

72. Fu RG, Sun Y, Sheng WB, Liao DF. Designing multi-targeted agents: an emerging anticancer drug discovery paradigm. Eur J Med 
Chem 2017;136:195-211. DOI PubMed

73. Bérubé G. An overview of molecular hybrids in drug discovery. Exp Opin Drug Discov 2016;11:281-305. DOI PubMed

74. Rosati R, Chen B, Patki M, et al. Hybrid enzalutamide derivatives with histone deacetylase inhibitor activity decrease heat shock protein 90 and androgen receptor levels and inhibit viability in enzalutamide-resistant prostate cancer cells. Mol Pharmacol 2016;90:225-37. DOI PubMed PMC

75. Hu W-Y, Xu L, Chen B, et al. Targeting prostate cancer cells with enzalutamide-HDAC inhibitor hybrid drug 2-75. Prostate 2019;79:1166-79. DOI PubMed

76. Lai C-J, Bao R, Tao X, et al. CUDC-101, a multitargeted inhibitor of histone deacetylase, epidermal growth factor receptor, and human epidermal growth factor receptor 2, exerts potent anticancer activity. Cancer Res 2010;70:3647-56. DOI PubMed

77. Sun H, Mediwala SN, Szafran AT, Mancini MA, Marcelli M. CUDC-101, a novel inhibitor of full-length androgen receptor (flAR) and androgen receptor variant 7 (AR-V7) activity: mechanisms of action and in vivo efficacy. HORM CANC 2016;7:196-210. DOI

78. Li X, Kamenecka TM, Cameron MD. Cytochrome P450-mediated bioactivation of the epidermal growth factor receptor inhibitor erlotinib to a reactive electrophile. Drug Metab Dispos 2010;38:1238-45. DOI PubMed PMC

79. Gass-Jégu F, Gschwend A, Gairard-Dory AC, et al. Gastrointestinal perforations in patients treated with erlotinib: a report of two cases with fatal outcome and literature review. Lung Cancer 2016;99:76-78. DOI PubMed

80. Galloway TJ, Wirth LJ, Covelas AD, et al. A phase I study of CUDC-101, a multitarget inhibitor of HDACs, EGFR, and HER2, in combination with chemoradiation in patients with head and neck squamous cell carcinoma. Clin Cancer Res 2015;21:1566-73. DOI PubMed PMC

81. Wu CP, Hsiao SH, Su CY, et al. Human ATP-Binding Cassette transporters ABCB1 and ABCG2 confer resistance to CUDC-101, a multi-acting inhibitor of histone deacetylase, epidermal growth factor receptor and human epidermal growth factor receptor 2. Biochem Pharmacol 2014;92:567-76. DOI PubMed

82. Yanase K, Tsukahara S, Asada S, Ishikawa E, Imai Y, Sugimoto Y. Gefitinib reverses breast cancer resistance protein-mediated drug resistance. Mol Cancer Ther 2004;3:1119-25. PubMed

83. Leggas M, Panetta JC, Zhuang Y, et al. Gefitinib modulates the function of multiple ATP-binding cassette transporters in vivo. Cancer Res 2006;66:4802-7. DOI PubMed

84. Goehringer N, Biersack B, Peng Y, et al. Anticancer activity and mechanisms of action of new chimeric EGFR/HDAC-inhibitors. Int J Mol Sci 2021;22:8432. DOI PubMed PMC

85. Qian C, Lai C-J, Bao R, et al. Cancer network disruption by a single molecule inhibitor targeting both histone deacetylase activity and phosphatidylinositol 3-kinase signaling. Clin Cancer Res 2012;18:4104-13. DOI PubMed

86. Hu C, Xia H, Bai S, et al. CUDC-907, a novel dual PI3K and HDAC inhibitor, in prostate cancer: antitumor activity and molecular mechanism of action. J Cell Mol Med 2020;24:7239-53. DOI PubMed PMC

87. Landsburg DJ, Barta SK, Ramchandren R, et al. Fimepinostat (CUDC-907) in patients with relapsed diffuse large B cell and highgrade B-cell lymphoma: report of a phase 2 trial and exploratory biomarker analyses. Br J Haematol 2021;195:201-9. DOI PubMed

88. Wu CP, Hsieh YJ, Hsiao SH, et al. Human ATP-Binding Cassette transporter ABCG2 confers resistance to CUDC-907, a dual inhibitor of histone deacetylase and phosphatidylinositol 3-kinase. Mol Pharmaceutics 2016;13:784-94. DOI PubMed 